\title{
Critical analysis of correlation and heritability phenomenon in the silkworm, Bombyx mori (Lepidoptera: bombycidae)
}

\author{
Tribhuwan Singh, Madan Mohan Bhat, Mohammad Ashraf Khan
}

Regional Sericultural Research Station, Research Extension Centre, Central Silk Board, Ministry of Textiles, Government of India, Himachal Pradesh, India.

E-mail: tnspriya@yahoo.com

Received 14 January 2011; revised 9 March 2011; accepted 6 August 2011.

\begin{abstract}
Correlation and heritability studies of quantitative traits are a pre-requisite for judicious selection for genetic improvement of complex characters of economic importance. The success of selection is governed by the degree to which the desired trait is transmitted to the succeeding generation. The nature of selection is to be given due consideration at appropriate developmental stages for pursuing selection in desired direction while improving or evolving high productive breeds or hybrids of the silkworm. Characters showing high heritability as well as high genetic advance respond better to simple phenotypic selection while those having low heritability and low genetic advance may respond better to mass selection. Characters showing high heritability and low genetic advance may yield good response to hybridization and recurrent selection. An attempt has been made in this review article to briefly discuss the magnitude of correlation and heritability in selection strategies for the improvement of quantitative traits in desired direction in the silkworm, Bombyx mori (L.).
\end{abstract}

Keywords: Bombyx Mori; Correlation; Heritability

\section{INTRODUCTION}

The knowledge of relationship between quantitative characters of economic importance determining silk productivity is of paramount importance to the breeders, cocoon and egg producers, reelers, weavers, twisters, buyers etc. [1]. While egg producers favor strong potential genotypes producing more number of eggs, cocoon growers are interested in the genotype having healthy larvae and producing high cocoon yield. The filature industry favors high reelability, high percentage of raw silk and superior quality of cocoons and weaving industry requires better neatness, denier, high tenacity and elongation.
For these, we can not wait for favors from nature, but we must rest them from her and it is possible only through man's intervention to force any form of individual to change more quickly in the direction desirable to them. Various methods are advocated for improving the quantitative characters in desired direction, which includes breeding (cross breeding, inbreeding, out-breeding and hybridization), selection, mutation etc. But, whatever system is followed, genetic improvement of quantitative characters is not possible without judicious selection. In other words, selection is the measure of permanently changing the relative proportions of various genes present in the original stock.

Estimation of correlation and heritability in the genetic studies of quantitative characters are of special significance for selection, as its magnitude indicates the accuracy with which a genotype can be recognized by its phenotypic expression [2-4]. It also helps in deciding upon a suitable selection criteria for the genetic improvement of complex characters. Thus, the knowledge of correlation and heritability of basic economic quantitative characters is a prerequisite for selection while creating, evaluating, improving or evolving high productive breeds, hybrids or strains of silkworm [5,6].

In this article an attempt has been made to discuss briefly the advances achieved in selection strategies in relation to correlation and heritability of quantitative characters while evolving or improving high productive breeds or hybrids of silkworm, Bombyx mori and its significance in breeding.

\section{SELECTION}

There are two principle methods of selection. They are-

\subsection{Pedigree Selection}

Pedigree selection is useful only when adequate information is available about the genotype. Essentially, pedigree selection is only an extension of performance testing of breeds since each individual's performance is 
tested and performance records are used to evaluate the related genotypes

\subsection{Mass Selection}

1) Tandem method of selection (directional selection): in this method, the selection is directed towards improvement of only one desired trait at one time and is continued till the goal set for this character is achieved. Thereafter, selection is made for another trait till the goal set for that trait is also achieved. Thus, in such cases the traits are selected one after the other. This is highly in-efficient method of selection, as unless the traits are genetically related, whatever achievement is made in the first trait in the first period is lost when attention is diverted to another trait. The rate of net improvement therefore becomes very small or sometimes negligible.

2) Independent culling method: in this method of selection, few parameters are considered at a time. For each parameter, minimum standard is set. The genotype must meet the minimum standard set for each of the trait; otherwise, it is to be rejected from the breeding population. If any genotype is exceptionally good in one parameter, but is bad in another parameter, it is being totally rejected. The effectiveness of this method therefore, depends on the standard chosen for each of the traits. If very high standards are fixed, the number of genotypes selected to become the parents will be very few, resulting in gradual extinction of the genotypes. On the other hand, if very low standard is set, the selection of genotype based on merit will become difficult, as most of the genotypes fulfill the set standard. Besides, fixing an arbitrary standard for each trait, it is also necessary to determine as to how many traits are to be considered at a time. This is because selection for several traits at a time reduces the selection intensity of the trait. Therefore, selection for unimportant traits should be avoided as far as possible as it reduces progress in improvement in important traits. Emphasis should be given on one or two traits, which are economically more important than the others and have the capacity to respond.

3) Selection index (simultaneous selection): the most effective method of selection is by selection index. A selection index is used when the breeder simultaneously selects many desirable economic traits to improve it in a desired direction. The theory and practice of developing an index is called "Applied Quantitative Genetics" [7]. Procedure for calculation of selection index varies from breeder to breeder. Restricted selection index, modified base index [8], weight-free index for ranking genotypes [9] are some of the method in practice.

Various authors under different sets of restrictions have done theoretical comparisons among these types of selection. According to generalized formula [10] expected change in genotypic worth in response to selection for a single trait is proportional to the ratio of covariance. If any of these ratios is far larger than any other, tandem selection for that trait or independent culling with high selection intensity for that trait, should give response to overall genotypic value, which are close to that expected from index selection [11]. Index selection is found to be better than tandem selection for improving genotypic value for negatively correlated characters but selection quite often does not follow the regular pattern predicted by "Quantitative Genetics Theory" [12]. One of the most striking manifestations of the irregularities is the "Reversed Response" when selecting individuals for the increased value of character, results in a decreased value among their offspring and viceversa [13]. A reversed response in selection experiments is rarely being given serious consideration and its significance is usually dismissed with one of the two explanations - a sudden change in environmental conditions or random drift. Caution is needed, however, before either of the two explanations is accepted in a particular case because either of the explanation under the laboratory experiments is highly improbable where conditions are kept under control by the experimenter.

Therefore, to obtain desirable results, it is of paramount importance to find out the type of correlations existing between various quantitative parameters and their heritability under set environmental conditions before initiating any form of selection.

\section{CORRELATION}

The degree of association or relationship between two variables is measured by correlation coefficient (r). The correlation coefficient may be positive or negative. Positive correlation indicates that the two variables are varying in the same direction. In other words, if one variable increases, the other variable also increases. In negative correlation, the two variables vary in opposite direction, i.e. if one variable increases the other decreases. There is very intimate correlation between some of the characters in silkworm and an excellent character may bring down the merit of another character, if not given due consideration at the appropriate developmental stage. Correlation between different pairs of quantitative characters studied [4] revealed high significant $(P<0.01)$ positive values between cocoon weight and pupal weight $(\mathrm{r}=$ $+0.994)$, cocoon weight and shell weight $(r=+0.614)$, pupal weight and shell weight $(\mathrm{r}=+0.527)$, while significant $(\mathrm{P}<0.01)$ negative values between pupal weight and cocoon shell ratio $(\mathrm{r}=-0.827)$ (Table 1). This indicates that selection by cocoon weight would lead to increase of pupal weight and shell weight but selection by 
Table 1. Correlation co-efficient between some pairs of economic characters in Bombyx mori.

\begin{tabular}{cccc}
\hline $\begin{array}{c}\text { Correlation } \\
\text { between }\end{array}$ & $\begin{array}{c}\text { Pupal } \\
\text { weight }\end{array}$ & Shell weight & Cocoon-shell ratio \\
\hline Cocoon weight & $+0.994^{* *}$ & $+0.614^{* *}$ & $-0.764^{* *}$ \\
Pupal weight & & $+0.527^{* *}$ & $-0.827^{* *}$ \\
Shell weight & & & +0.035 \\
\hline
\end{tabular}

**Significant at $1 \%$ level of significance.

pupal weight would lead to decrease of cocoon shell ratio.

Correlation studies (Table 2) performed to establish the relationship between female pupal weight and fecundity indicated highly significant $(\mathrm{P}<0.01)$ positive correlation between the two, irrespective of their weight [14]. Fecundity has been found increasing from lower pupal weight to higher pupal weight [15]. Similar observation was also made by other authors $[1,14,16]$. Hence, selection by female pupal weight will automatically lead to increased fecundity. Positive values of correlation coefficient in the regression analysis also clearly indicated that selection of individuals for higher fecundity depends on its pupal weight but extreme pupal weight should be avoided as it may sometimes lead to bottleneck phenomenon [17]. Therefore, selection of moderate pupal weight should only be encouraged for egg production, as it also determines increased larval weight, survival rate, filament length etc. in the successive generations [18].
Fecundity, which has been found showing positive correlation with female pupal weight [4] has also shown highly significant $(\mathrm{P}<0.01)$ positive correlation with cocoon weight and cocoon shell weight (Table 3). Hence, selection for higher cocoon weight, pupal weight and shell weight together would yield higher fecundity. Correlated quantitative traits of economic importance in the silkworm Bombyx mori is summarized in Table 4. As fecundity is positively correlated with pupal weight $[16,19]$ but negatively with productivity, cocoon-shell ratio and robustness every effort should be made for the improvement of negatively correlated characters without reducing the fecundity.

Cocoon yield, a very important character linked directly with the earning of Sericulturists is positively correlated with survival rate. Cocoon weight, which is being given always much emphasis in selection strategies, has shown positive correlation with shell weight $[3,20,21]$ and pupal weight [22]. A high positive correlation is also established between shell weight and filament length/ silkiness [23,24]. Filament length has also been found positively correlated with shell ratio [24,25] and neatness. Positive correlation is also being reported between lousiness and ratio of degumming loss [26]. Therefore, when selection is enforced in the directions of high lousiness, the ratio of degumming loss increases. Generally, lousiness is more in Japanese strains and less in Chinese strains. It is more in cocoons with high shell

Table 2. Correlation and regression between female pupal weights and fecundity in the silkworm Bombyx mori.

\begin{tabular}{|c|c|c|c|c|}
\hline $\begin{array}{l}\text { Female Pupal weight } \\
\text { (gm) }\end{array}$ & $\begin{array}{l}\text { Average pupal weight } \\
\text { (X) }\end{array}$ & Average fecundity & $\begin{array}{c}\text { Correlation coefficient } \\
\text { (r) }\end{array}$ & $\begin{array}{c}\text { Regression of fecundity } \\
\text { on pupal weight (Y) }\end{array}$ \\
\hline $1.000-1.20$ & 1.12308 & 443.600 & $+0.8720 * *$ & $Y=-38.7688+429.5053 X$ \\
\hline $1.201-1.30$ & 1.24280 & 468.040 & $+0.9209 * *$ & $Y=1873.5294+1884.1080 X$ \\
\hline $1.301-1.50$ & 1.41356 & 487.880 & $+0.8646 * *$ & $Y=510.7906+706.4933 X$ \\
\hline $1.501-1.70$ & 1.54728 & 535.360 & $+0.8456^{* *}$ & $Y=398.0606+603.2656 X$ \\
\hline $\begin{array}{l}\text { Pooled data } \\
1.000-1.80\end{array}$ & 1.41422 & 498.831 & $+0.7820 * *$ & $Y=187.6987+220.0028 X$ \\
\hline
\end{tabular}

**Significant at $1 \%$ level of significance.

Table 3. Correlation between fecundity, cocoon weight and shell weight in Bombyx mori.

\begin{tabular}{|c|c|c|c|c|}
\hline \multirow{2}{*}{ Cocoon weight (gm) } & \multirow{2}{*}{ Shell weight (cg) } & \multirow{2}{*}{ Fecundity (No.) } & \multicolumn{2}{|c|}{ Correlation between fecundity and } \\
\hline & & & Cocoon weight & Shell weight \\
\hline $1.38 \pm 0.162$ & $24.1 \pm 5.38$ & $437 \pm 143$ & $+0.765^{* *}$ & $+0.643^{* *}$ \\
\hline $1.58 \pm 0.149$ & $28.9 \pm 3.22$ & $558 \pm 66$ & $+0.785^{* *}$ & $+0.695^{* *}$ \\
\hline $1.76 \pm 0.193$ & $36.0 \pm 4.64$ & $566 \pm 72$ & $+0.866^{* *}$ & $+0.716^{* *}$ \\
\hline $1.88 \pm 0.157$ & $39.5 \pm 4.84$ & $632 \pm 83$ & $+0.584 * *$ & $+0.625^{* *}$ \\
\hline
\end{tabular}

**Significant at $1 \%$ level of significance. 
Table 4. Significantly correlated characters in the silkworm Bombyx mori.

\begin{tabular}{llc}
\hline Correlation between & Correlation & References \\
\hline Fecundity and robustness & Negative & Gowda et al., 1988 [19] \\
Fecundity and female pupal weight & Positive & Jayaswal et al., 1991 [16] \\
Cocoon weight and larval weight & Positive & Satenahalli et al., 1990 [29] \\
Cocoon weight and shell weight & Positive & Petkov, 1981a [3] \\
Cocoon weight and filament length & Positive & Petkov, 1981c [21] \\
Cocoon weight and pupal weight & Positive & Rajanna and Reddy, 1990a [22] \\
Cocoon weight and denier & Positive & Satenahalli et al., 1990 [29] \\
Female pupal wt. and larval weight & Positive & Gowda et al. 1989 [18] \\
Cocoon weight and cocoon silkiness & Positive & Grekov and Petkov. 1990 [30] \\
Shell weight and cocoon weight & Positive & Ozdzensky and Kremky, 1987 [31] \\
Shell weight and pupal weight & Positive & Singh et al., 1992a [20] \\
Shell weight and cocoon silkiness & Positive & Long and Petkov, 1987 [23] \\
Shell weight and filament length & Positive & Petkov, 1981b [24] \\
Shell ratio and cocoon quality & Positive & Singh et al., 1992b [28] \\
Shell ratio and pupal weight & Negative & Singh et al., 1992a [20] \\
Shell ratio and filament length & Positive & Petkov, 1981b [24] \\
Filament length and reelability & Negative & Jayaswal et al., 1990 [5] \\
Yield of cocoons of parent and their hybrids & Positive & Jonka, 1986 [27] \\
Reelability and tenacity & Positive & Liu and He, 1991 [32] \\
Length and size of filament & Positive & Miyahara, 1978 [26] \\
\hline
\end{tabular}

weight. As degumming trait is closely correlated with cocoon shell weight, it is not quite easy to have a genotype showing low value for degumming trait without reducing the cocoon shell weight.

Reelability of cocoons is one of the most important parameter which needs attention in the improvement programme, but, it is very complicated character to be improved upon, because it is negatively correlated with filament length [5] and positively with neatness and the expression of which differs with environmental conditions viz., temperature, humidity, light and air current during spinning period [27]. The qualities of cocoons and fixation of price are usually assessed based on cocoon and shell weights but shell ratio is a better parameter for assessing the cocoon quality for reeling because higher shell percentage leads higher raw silk yield due to their positive correlation. A positive correlation is being established between shell ratio and cocoon quality [28], whereas, cocoon weight and shell weight does not necessarily show positive correlation with reeling performance (Table 4).

It has been reported that there is a significant positive correlation between cocoon weight and pupal weight, cocoon shell weight, maximum larval weight, single cocoon filament length, pupal duration, denier, fecundity and hatchability [29], larval weight and pupal weight
[18]. Therefore, selection should be done for robust larvae (disease free) with higher larval weight. Usually, high productive worms show less viability, which is evident from the fact that poor productivity and higher resistance for diseases are associated together in indigenous genotypes, while high productivity and poor resistance for diseases in bivoltine breeds.

Genetic analysis of different quantitative traits indicated incomplete dominance for growth rate, raw silk percentage, filament length, filament size and reelability percentage; over dominance for pupation rate and cocoon weight and epistatic effect for pupation rate, cocoon weight, filament size and reelability percentage. Further, cytoplasmic effects were also observed in pupation rate and size of cocoon filament. As a result cocoon weight, pupation rate and cocoon yieldingness could be considered to improve by heterosis in F1 hybrids, while other characters are improved by selection. Especially, reelability of cocoons is expected to improve by the accumulation of dominant genes under the control of environmental conditions.

\section{HERITABILITY}

Heritability is a property of certain character of the population and of the environment to which silkworms are subjected. Every character of an organism is both 
hereditary and environmental as it is manifested because of long chain interactions of genes either with each other or with the environment. In fact, characters cannot be developed until and unless the genes governing them have proper environment. Heritability of quantitative traits plays very vital role in the selection strategies. One of the most important function of the heritability in genetic studies of metric character is, its predictive role, expressing the reliability of the phenotypic value as a guide to the breeding value. With the genetic or environmental variations, the heritability estimates also change. The heritability of characters cannot be estimated from one population or one set of environmental conditions to another [1].

\section{Determination of Heritability}

Heritability is determined in two ways:

1) Broad sense heritability: in broad sense, heritability is the ratio of the total genotypic variance to that of total phenotypic variance. It is useful in predicting the outcome of artificial selection among clones, inbred lines, varieties etc.

2) Narrow sense heritability: in narrow sense, heritability is the ratio of additive genetic variance (VA) to the total phenotypic variance (VP) and this method is of great importance to breed improvement. It is used when artificial selection is practiced in a randomly mating population. In narrow sense, generally, heritability of a character is smaller than the broad sense heritability. Heritability is expressed either $0-100$ or $0-1$. Heritability estimates of different characters can be determined by the following three factors:

- Correlation regression analysis of close relatives (for example parent—offspring, full—sibs, half—sibs etc.).

- Correlation response in which both desired and undesired characters are selected.

- Analysis of variance components.

It is important to realize that the heritability is a property not only for a character but also of the population and of the environmental circumstances to which the individuals are subjected. Heritability studies (Table 5) conducted for some important quantitative traits reveals higher values for shell weight $(80.20 \%)$, growth rate (79.30\%), raw silk percentage $(79.00 \%)$, pupal weight (78.50\%), cocoon-shell ratio $(72.40 \%)$ and cocoon weight (73.60\%), while extremely low for reelability (28.00\%) and pupation rate (19.00\%) [4]. The heritability estimates for various quantitative traits reveals higher values for fecundity and filament length, cocoon weight and pupal weight [33], cocoon-shell weight, growth rate [34], raw silk percentage [35] and cocoon-shell ratio [36], while low or extremely low for pupation rate and reelability percentage [35]. These characters with low
Table 5. Heritability of some economic traits in Bombyx mori.

\begin{tabular}{cc}
\hline Characters & Heritability \\
\hline Cocoon weight & 73.60 \\
Pupal weight & 78.50 \\
Cocoon-shell ratio & 72.40 \\
Pupation rate & 19.00 \\
Shell weight & 80.20 \\
Growth rate & 79.30 \\
Raw silk \% & 79.00 \\
Reelability & 28.00 \\
\hline
\end{tabular}

values of heritability are of little importance in selection strategies because here most variations are non-transmissible. Characters with high heritability as well as high genetic advance indicating possible operation of additive gene action and hence respond better to simple phenotypic selection than those having low heritability and low genetic advance [2]. Therefore, individual selection for those having high heritability and high genetic advance has to be resorted for obtaining results in desirable direction. However, precision can be improved if selection is aimed on two groups of parents, one with high heritability values and the other with low values for the character under selection and offspring are reared only from these selected groups [12].

On the contrary, moth emergence, effective rate of rearing [2], larval and pupal duration [37] showing moderate to high heritability, but low genetic advance reveals operation of predominant non-additive gene action and hence responds better to hybridization and recurrent selection. Mostly, selection does not act on a single character but act on whole set of characters [38] and when phenotypic correlation exists among characters, selection on a character may result in selection differentials on correlated characters [39]. Since expression of economic characters depends upon a number of related attributes, genetic progress will be accelerated only if selection is performed simultaneously on more than one attribute, contributing to the theme. Studies conducted on phenotypic and genotypic coefficient of variability, heritability and genetic advance [29] revealed that cocoon shell weight, cocoon filament length and maximum larval weight showed high heritability and genetic advance, and high phenotypic and genotypic coefficients of variability. Seasons also have some influence on heritability of various characters. The traits like silk filament, size of the filament, silk content and cocoon-shell ratio has high heritability in favorable seasons compared to unfavorable ones. Thus, heritability is an important tool in predicting the magnitude and speed of population improvement. With the help of heritability estimates, a 
breeder can know how much more closely related organisms with similar genotypes resemble each other than less closely related organisms. It is also useful in predicting the outcome of artificial selection among the clones, inbred lines, and varieties besides production of superior genotypes $[1,40]$.

Therefore, relations between different pairs of characters and the degree of its manifestation should be taken into consideration while performing selection keeping in view the magnitude of the objectives.

\section{REFERENCES}

[1] Singh, T. and Saratchandra, B. (2004) Principles and techniques of silkworm seed production. Discovery Publishing House, New Delhi, 342.

[2] Narasimharaju, R., Govindan, R., Ashoka, J. and Rayar, S.G. (1990) Genetic variability for quantitative traits in silk-worm, Bombyx mori (L). Entomon, 15, 197-201.

[3] Petkov, N. (1981a) The possibility of forecasting the effectiveness of selecting lines of the silkworm, Bombyx mori based on weight and silk content of cocoons. Selskotopanska Nauka, 19, 92-96.

[4] Singh, T., Chandrashekharaiah, A. and Samson, M.V. (1994) Selection strategies in relation to correlation and heritability in the silkworm, Bombyx mori (L). Bulletin of Sericultural Research, 5, 37-41.

[5] Jayaswal, K.P., Singh, T. and Sen, S.K. (1990) Correlation between some economic parameters and their application in silkworm breeding. Indian Silk, 29, 25-27.

[6] Sabhat, A., Farooq, M., Sofi, A.M. and Malik, M.A. (2009) Heritability, genetic advance and correlation analysis of some reproductive traits in silkworm, Bombyx mori L. Journal of Experimental Zoology, 12, 307-310.

[7] Kempthorne, O. (1977) Status of quantitative genetic theory. Proceedings of International Conference on Quantitative Genetics, Iowa State University Press, Ames, 16-21 August 1976, 719.

[8] Barker, R.J. (1986) Selection indices in plant breeding. CRC Press, Inc., New York.

[9] Elston, R.C. (1963) A weight-free index for the purpose of ranking or selection with respect to several traits at a time. Biometrics, 19, 85. doi:10.2307/2527573

[10] Finney, D.J. (1962) Genetics gains under three methods of selection. Genetical Research, 3, 417. doi:10.1017/S0016672300003256

[11] Hajian, E., Seidavi, A. and Lavvaf, A. (2011) Estimation of response to selection in three silkworm commercial pure lines with oval cocoons. Annals of Biological Research, 2, 215-225.

[12] Falconer, D.S. (1981) Introduction to quantitative genetics. 2nd Edition, Longman Inc., New York.

[13] Gimelfarb, A. (1986) Multiplicative genotype-environmental interaction as a cause of reversed response to directional selection. Genetics, 114, 333-343.

[14] Singh, T. (1994) Correlation between pupal weight and fecundity in Bombyx mori (L). Annals of Entomology, 12, 5-7.

[15] Singh, T., Bhat, M.M. and Khan, M.A. (2010) Silkworm egg science-Principles \& protocols. Daya Publishing House, New Delhi, 277.
[16] Jayaswal, K.P., Singh, T. and Subba, R.G. (1991) Effect of female pupal weight on fecundity of mulberry silkworm Bombyx mori. Indian Journal of Sericulture, 30, 141-143.

[17] Basavaraja, H.K., Suresh, K.N., Mal, R.N. and Datta, R.K. (1998) New approaches to bivoltine silkworm breeding; in Silkworm breeding. Oxford and IBH Publishing Co. Pvt. Ltd., New Delhi, 131-139.

[18] Gowda, B.L.V., Sannaveerappanayar, V.T. and Shivayogeshwar, B. (1989) Fecundity and hatchability in mulberry silkworm, Bombyx mori (L.) as influenced by pupal weight. International Congress on Tropical Sericultural Practices, Part VI, Bangalore, 18-23 February 1989, 2124

[19] Gowda, B.L.V., Narayanaswamy, T.K. and Munirajappa, R. (1988) Impact of pupal weight on growth and development of the following generation in the silkworm Indian race NB7 (Bombyx mori). Sericologia, 29, 481489.

[20] Singh, T., Jayaswal, K.P. and Subba, R.G. (1992a) Correlation studies between some breeding parameters of silkworm, Bombyx mori (L). Journal of Zoological Research, 5, 47-50.

[21] Petkov, N. (1981c) Phenotypic correlations and regressions between some silkworm (Bombyx mori) breeding characters. Genetics Selection, 14, 386-390.

[22] Rajanna, G.S. and Reddy, G.S. (1990a) Studies on the variability and interrelationship between some quantitative characters in different breeds of silkworm, Bombyx mori L. Sericologia, 30, 67-74.

[23] Long, N.V. and Petkov, N. (1987) Breeding-Genetic studies in some silkworm (Bombyx mori) breeds. I. Variability and correlations of quantitative characters. Genetics Selection, 20, 58-62.

[24] Petkov, N. (1981b) Variability and correlations between some characteristic features of silkworm (Bombyx mori L). Zhivotnov'd Nauki, 18, 83-86.

[25] Ghanipoor, M., Mirhosseini, S.Z., Seidavi, A.R., Shadarvar, A. and Bizhannia, A.R. (2007) Effect of selection index in line level on cocoon shell weight and cocoon shell percentage of silkworm, Bombyx mori L. commercial hybrids. Proceeding of 2nd Animal Science Congress, Guilan University, Rasht, 4-5 September 2007, pp. 181182.

[26] Miyahara, T. (1978) Selection of long filament length basic variety. I. Effect of selection in the later generations. Acta Sericologia, 106, 73-78.

[27] Jonaka, N. (1986) Some parameters of basic quantitative breeding characters in silkworm, Bombyx mori. II. Correlations between the basic breeding characters. Genetics Selection, 19, 144-150.

[28] Singh, T., Singh, K. and Das, M. (1992b) Astounding effect of correlated parameters in silk industry. Indian Textile Journal, 102, 26-30.

[29] Satenahalli, S.B., Govindan, R., Goud, J.V. and Magdum, S.B. (1990) Genetic parameters and correlation coefficient analysis in silkworm, Bombyx mori. Mysore Journal of Agricultural Sciences, 24, 491-495.

[30] Grekov, D. and Petkov, N. (1990) Correlation between some traits and possibilities for prognostication heterosis of F1 crosses on hybridization of Bombyx mori L. Zhivotnov's Nauki, 27, 80 
[31] Ozdzenska, B. and Kremky, J. (1987) Estimation of heritability and genotypic, phenotypic and environmental correlations in out-bred populations of mulberry silkworm, Bombyx mori L. Sericologia, 27, 633-638.

[32] Liu, Q.-X. and He, S.-M. (1991) Studies on the efficiency of selection for improving technological characters of cocoon filament of Bombyx mori L. Canye Kaxue, 17, 7579.

[33] Yan, L.L. (1983) The estimates of heritability of pupal weight, cocoon weight and number of eggs laid in the silkworm (Bombyx mori) and its genetic correlation between these characters and path coefficient analysis. Journal of Sericultural Sciences of China, 9, 149-155.

[34] Rajanna, G.S. and Reddy, G.S. (1990b) New dimensions in tropical silkworm race breeding. Indian Silk, 28, 8-12.

[35] Gamo, T. and Hirabayashi, T. (1983) Genetic analysis of growth rate, pupation rate and some quantitative characters by diallel cross in the silkworm, Bombyx mori. Japanese Journal of Breeding, 33, 178-190.
[36] Singh, T. and Singh, K. (1993) Heritability and correlations between some economic characters in Bombyx mori (L). Science \& Culture, 59, 51-52.

[37] Ashoka, J. and Govindan, R. (1990) Genetic estimates for quantitative traits in bivoltine silkworm, Bombyx mori L. Mysore Journal of Agricultural Sciences, 24, 371-374.

[38] Lande, R. and Arnold, S.J. (1983) The measurement of selection on correlated characters. Genetics Selection, 20, 58-62.

[39] Arnold, S.J. and Wade, M.J. (1984) On the measurement of natural and sexual selection: Theory. Evolution, 38, 709-719. doi:10.2307/2408383

[40] Seidavi, A., Mirhosseni, Z., Mavvajpour, M. Ghanipoor, M., Bizhannia, A., Qotbi, A. and Chamani, M. (2009) Additive genetic variations and selection index changes of economic traits of the silkworm commercial pure lines against parent selection pressure. American-Eurasian Journal of Agriculture and Environmental Sciences, 6, 460465. 